\title{
Autoimmune encephalitis: a review of diagnosis and treatment
}

\author{
Encefalites autoimunes: uma revisão sobre diagnóstico e tratamento \\ Livia Almeida Dutra ${ }^{1,2}$, Fabiano Abrantes ${ }^{1}$, Fabio Fieni Toso ${ }^{1}$, José Luiz Pedroso', Orlando Graziani Povoas \\ Barsottini', Romana Hoftberger ${ }^{3}$
}

\begin{abstract}
Autoimmune encephalitis (AIE) is one of the most common causes of noninfectious encephalitis. It can be triggered by tumors, infections, or it may be cryptogenic. The neurological manifestations can be either acute or subacute and usually develop within six weeks. There are a variety of clinical manifestations including behavioral and psychiatric symptoms, autonomic disturbances, movement disorders, and seizures. We reviewed common forms of AIE and discuss their diagnostic approach and treatment.
\end{abstract}

Keywords: encephalitis; antibodies, neoplasm; status epilepticus; anti-N-Methyl-D-Aspartate receptor encephalitis; immunoglobulin; rituximab.

\section{RESUMO}

As encefalites autoimunes (EAl) são a principal causa de encefalite não-infecciosa. As manifestações neurológicas são variadas, incluindo alterações comportamentais ou psiquiátricas, disautonomia, transtornos do movimento e epilepsia. Habitualmente a instalação dos sintomas ocorre em até 6 semanas, de forma aguda ou subaguda. As EAl podem ser desencadeadas por tumores, quadros infecciosos virais ou ainda apresentar etiologia criptogênica. Este artigo revisa as principais EAl, estratégias de diagnóstico e tratamento.

Palavras-chave: encefalites; anticorpos antineoplásicos; status epiléptico; encefalite antirreceptor de N-Metil-D-Aspartato;imunoglobulinas; rituximab.

Autoimmune encephalitis (AIE) is considered one of the most common causes of noninfectious acute encephalitis. It is estimated that $20 \%$ of all encephalitis cases in northern Europe are immune-mediated ${ }^{1}$. The California Encephalitis Project found that anti-N-methyl-D-aspartate receptor (anti-NMDAR) encephalitis occurred in $47 \%$ of patients under 30 years of age ${ }^{2}$. Autoimmune encephalitis is typically an acute or subacute onset and that may become chronic later ${ }^{3}$. Suggested mechanisms that may trigger AIE include tumors (paraneoplastic), infections (parainfectious), or it may be cryptogenic ${ }^{4}$.

Autoimmune encephalitis has a wide variety of clinical manifestations including behavioral and psychiatric symptoms, autonomic disturbances, movement disorders and seizures $^{3,5}$. We reviewed common causes of AIE and discuss their pathophysiology, diagnostic approach and management.

\section{Pathophysiology of autoimmune encephalitis: an overview}

Autoimmune encephalitis presents an immune response against neuronal autoantigens with production of antibodies ${ }^{6}$.
Anti-neuronal antibodies are classified into antibodies against cell surface antigens (CSAab), antibodies against synaptic antigens (SyAab) and antibodies against intraneuronal antigens (INAab), also known as onconeural antibodies ${ }^{6,7}$.

The CSAab (i.e., anti-NMDAR antibodies) target molecules involved in neurotransmission leading to neuronal dysfunction ${ }^{7}$. They may have agonistic or antagonistic effects on the receptors, block ion channel pores or disrupt the interaction with neighboring molecules. They could also alter receptor localization at the membrane or cause receptor internalization, thus reducing cell surface expression of receptors? ${ }^{7}$. Moreover, they could lead to complement deposition and activation of natural killer cells resulting in cell death?

The SyAab are believed to contribute to alteration of neurotransmitter release. In contrast, INAab (i.e., anti-Hu, anti-Yo, anti-Ma) are most likely not directly pathogenic and probably an epiphenomenon of T-cell-mediated immune response ${ }^{7}$.

The term AIE is used to describe a group of neurological disorders with symptoms of limbic and extra-limbic dysfunction in association with CSAab or SyAab ${ }^{8}$. Patients may have antibodies

\footnotetext{
${ }_{1}^{1}$ Universidade Federal de São Paulo, Departamento de Neurologia e Neurocirurgia, Divisão de Neurologia Geral, São Paulo SP, Brasil;

${ }^{2}$ Hospital Israelita Albert Einstein, São Paulo SP, Brasil;

${ }^{3}$ Medical University of Vienna, Institute of Neurology, Vienna, Austria.

Correspondence: Lívia Almeida Dutra; Rua Pedro de Toledo, 650; 04039-002 São Paulo SP, Brasil; E-mail: Liviaadutra@hotmail.com

Conflict of interest: There is no conflict of interest to declare.

Received 18 March 2017; Received in final form 31 August 2017; Accepted 18 September 2017.
} 
of more than one type, and CSAab and SyAab may be present together with anti-INAab, especially in paraneoplastic AIE.

Patients with AIE associated with CSAab have a more favorable prognosis. In contrast, those with AIE associated with INAab often show limited response to immunotherapy and their symptoms are mostly irreversible due to T-cell-mediated neuronal damage ${ }^{6,7}$.

\section{Clinical manifestations}

Patients with AIE may present with a variety of movement disorders such as ataxia, dystonia, myoclonus, and orofacial dyskinesia. Seizures are the most common symptom and different types of seizures may be seen, including refractory status epilepticus ${ }^{9}$. Autonomic disturbances are also frequently reported such as sudoresis, hypertension, tachycardia and hypoventilation. Some patients may show involvement of the myenteric plexus and develop gastrointestinal manifestations (diarrhea, gastroparesis, and constipation). Sleep disturbances such as agrypnia excitata, insomnia, abnormal sleep movements and behaviors, sleep apnea, and hypersomnia are also found ${ }^{10}$. Some of these findings are suggestive of a certain type of encephalitis and may indicate a specific underlying antibody and tumor (Figure 1).

Table 1 summarizes the diagnostic criteria for limbic encephalitis. These include working memory deficits, mood changes, and often seizures within three months from onset. Many patients with AIE present with a broader spectrum of neurological symptoms. For improving the recognition of immune-mediated cases, diagnostic criteria for suspected AIE were recently established including criteria for seronegative AIE (Table 2). Definite soropositive AIE requires typical clinical picture and positive anti-neuronal antibodies

\section{Anti-NMDAR encephalitis}

Anti-N-methyl-D-aspartate receptor encephalitis is one of the most common causes of AIE and was originally described in 2007 in a cohort of 12 patients, 11 of them with ovarian teratomas ${ }^{11}$. This condition predominantly affects children and young female patients ${ }^{3}$. Underlying malignancies are found mainly in patients between the age of 12-45 years; most of them are ovarian teratomas (94\%), followed by extraovarian teratomas (2\%), and other tumors (4\%). Herpes simplex virus- 1 encephalitis appears to be a trigger for antiNMDAR encephalitis; most postherpetic AIE cases are now believed to be anti-NMDAR encephalitis.

Approximately $70 \%$ of patients present with prodromal symptoms such as fever, headache, nausea, vomiting, diarrhea, and flu-like symptoms, two weeks before the onset of neurological manifestations. Behavioral complaints, psychosis, delusions, hallucinations and paranoia, accompanied with memory deficits and language disturbance, are frequently found at an early stage ${ }^{3,12}$. The most common movement disorders are orofacial dyskinesias, choreoathethosis, and dystonia ${ }^{12}$. Patients may progress to catatonia or

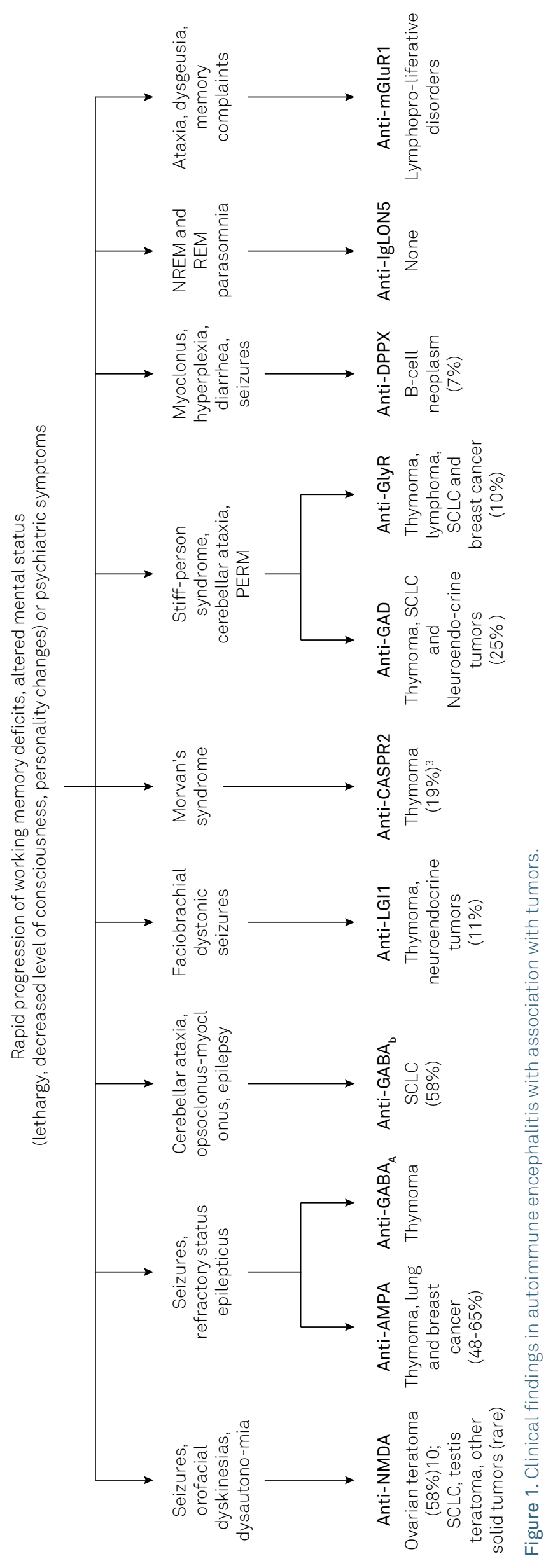


Table 1. Diagnostic criteria for definite autoimmune limbic encephalitis.

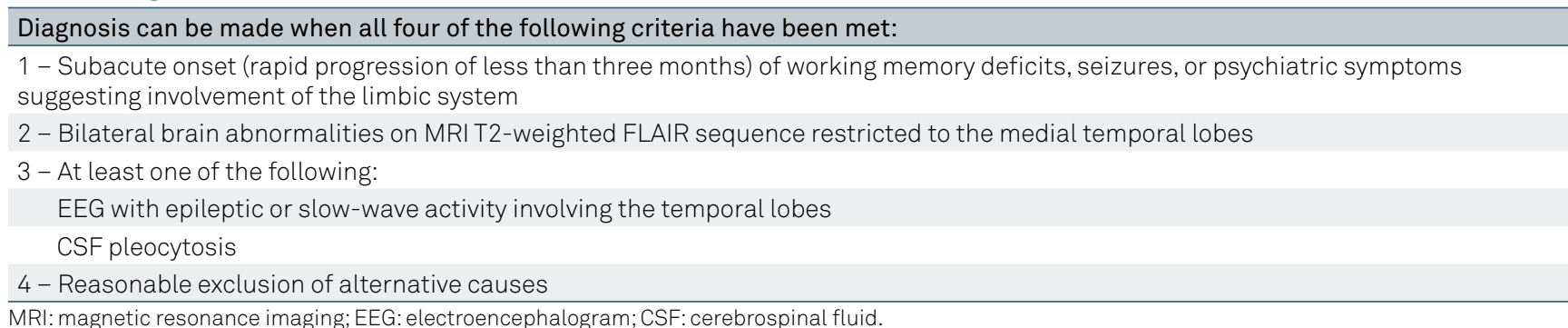

Table 2. Diagnostic criteria for autoimmune encephalitis.

Diagnostic criteria for possible autoimmune encephalitis (all three of the following criteria met):

1 - Subacute onset (rapid progression of less than three months) of working memory deficits (short-term memory loss), altered mental

status (decreased level of consciousness, lethargy or personality changes), or psychiatric symptoms

2 - At least one of the following:

New focal CNS findings

Seizures not explained by previously-known seizure disorder

CSF pleocytosis

MRI suggestive of encephalitis

3 - Reasonable exclusion of alternative causes

Criteria for autoantibody-negative but probable autoimmune encephalitis (all four criteria met):

1 - Subacute onset (rapid progression of less than three months) of working memory deficits (short-term memory loss), altered mental status (decreased level of consciousness, lethargy or personality changes), or psychiatric symptoms

2 - Exclusion of well-defined syndromes of autoimmune encephalitis (typical limbic encephalitis, Bickerstaff, brainstem encephalitis, acute disseminated encephalomyelitis)

3 - Absence of well-characterized autoantibodies in serum and CSF, and at least two of the following criteria:

MRI abnormalities suggestive of autoimmune encephalitis

CSF pleocytosis, oligoclonal bands or elevated CSF IgG index, or both

Brain biopsy showing inflammatory infiltrates and excluding other disorders

4 - Reasonable exclusion of alternative causes

CSF: cerebrospinal fluid; CNS: central nervous system.

mutism, followed by an altered level of consciousness and autonomic instability. An important differential diagnosis of anti-NMDAR encephalitis is neuroleptic malignant syndrome, because many patients are initially treated with neuroleptics for behavioral symptoms ${ }^{3,13}$. Table 3 summarizes the diagnostic criteria for anti-NMDAR encephalitis.

Seizures are seen in $16 \%$ of female and $34 \%$ of male patients; they can be focal seizures or patients may present with status epilepticus. Extreme delta brush is a specific electroencephalogram (EEG) pattern found in $30 \%$ of patients with anti-NMDAR encephalitis ${ }^{14}$. Children more frequently present with behavioral symptoms and movement disorders, whereas adults present with psychiatric symptoms and seizures.

Brain magnetic resonance imaging (MRI) is abnormal in $35 \%$ of patients at disease onset, but it may show late abnormalities in 50\%, mainly nonspecific hyperintense lesions in the grey and white matter. Rare cases show lesions suggestive of demyelination and overlap with demyelinating syndromes such as neuromyelitis optica spectrum disorders (NMOSD) associated with anti-aquaporin-4 antibodies or demyelinating diseases associated with myelin oligodendrocyte glycoprotein antibodies(MOG-ab) ${ }^{13}$.

\section{Anti-AMPAR encephalitis}

Patients with anti- $\alpha$-amino-3-hydroxy-5-methyl-4isoxazolepropionic acid receptor (anti-AMPAR) encephalitis characteristically present with seizures, memory impairment and psychosis. Some may develop sleep disturbances and movement disorders. Anti-AMPAR encephalitis is paraneoplastic in etiology in 64\% of cases, mostly associated with thymoma, ovarian teratoma and lung and breast cancer. Brain MRI shows T2 and FLAIR hyperintensities, particularly in the medial temporal lobe. Subcortical and cortical lesions, which are sometimes suggestive of demyelination, may also be found. Cerebrospinal fluid (CSF) examination may show pleocytosis and oligoclonal bands ${ }^{15}$.

\section{Anti-GABA-AR encephalitis}

Anti-gamma-aminobutyricacidAreceptor(anti-GABA-AR) encephalitis was first reported in 2014 in six patients (two male children, one female teenager and three male adults) ${ }^{16}$. They developed a rapidly progressive encephalopathy with early behavioral or cognitive changes that evolved with refractory seizures and multifocal lesions as seen on brain $\mathrm{MRI}^{16}$. In most of these patients, CSF analysis showed lymphocytic 
Table 3. Diagnostic criteria for anti-NMDA receptor encephalitis.

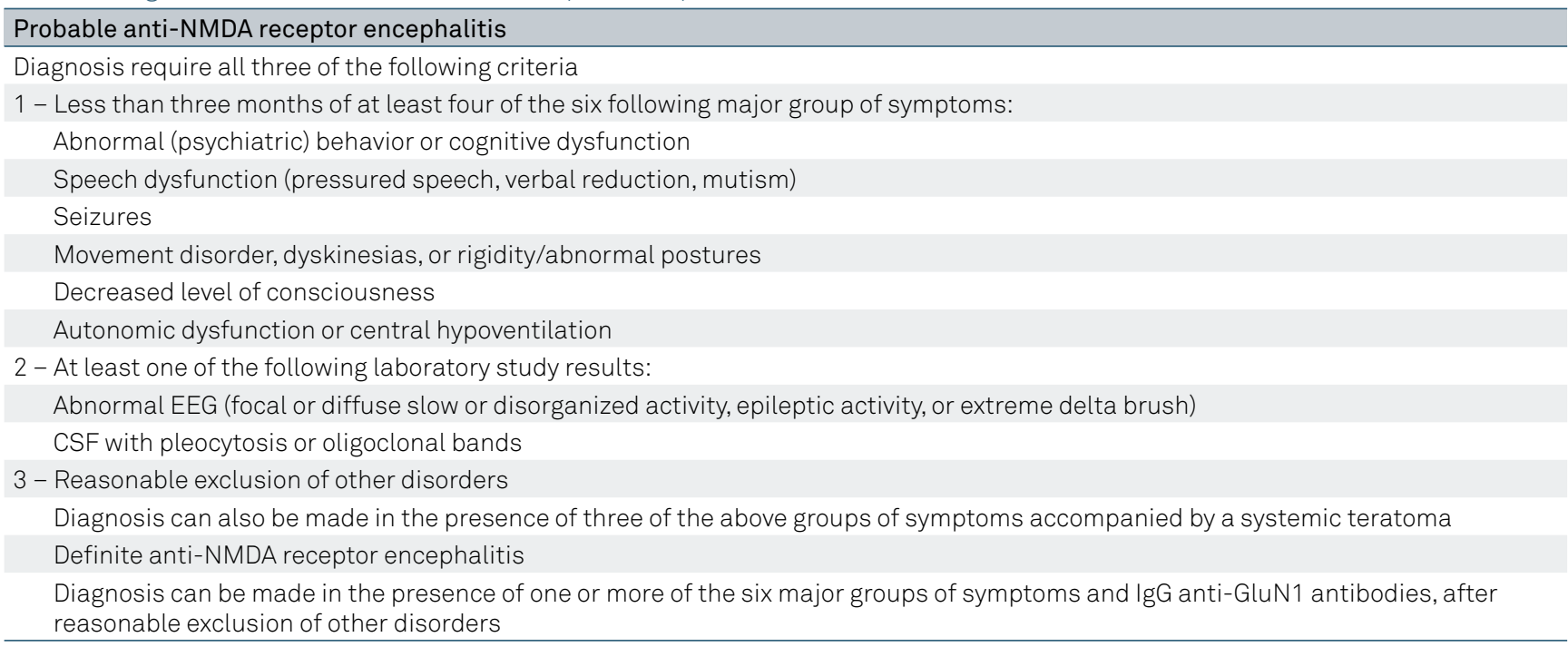

EEG: electroencephalogram;CSF: cerebrospinal fluid.

pleocytosis with or without oligoclonal bands. A recent study identified an underlying neoplasia in $27 \%$ of these patients, mostly thymomas ${ }^{17}$. Similar to that seen in patients with antigamma-aminobutyric acid B receptor (GABA-BR) and antiAMPAR antibodies, they may also present with coexisting autoimmune disorders such as thyroiditis or myasthenia ${ }^{18}$.

\section{Anti-GABA-BR encephalitis}

Anti-GABA-BR encephalitis is characterized by cognitive symptoms with severe seizures or status epilepticus ${ }^{19}$. Other presentations include ataxia and opsoclonus-myoclonus. In a small series of 20 patients with anti-GABA-BR, about $50 \%$ were found to have small-cell lung cancer ${ }^{20}$. Males and females appear to be equally affected. The long-term prognosis in anti-GABA-BR encephalitis is determined by the presence of an underlying malignancy ${ }^{21}$.

\section{Anti-LGI1 and anti-CASPR2 encephalitis (formerly known as anti-VGKC-associated encephalitis)}

The first reports of anti-voltage-gated potassium channel-complex antibodies (anti-VGKC) date back to 2001 and described patients with neuromyotonia, Morvan's syndrome and limbic encephalitis ${ }^{22}$. Other rare phenotypes included epilepsy and painful polyneuropathy ${ }^{23}$. Anti-VGKC antibodies, in fact, later turned out to be directed against proteins that form a complex with VGKC called leucine-rich gliomainactivated 1 (LGI1 and contactin-associated protein-like 2 (CASPR-2) $)^{24,25}$. Each of these antibodies presents with specific clinical symptoms.

The LGI1 is a secreted synaptic protein that interacts with transmembrane proteins ADAM22 and ADAM23 to form a trans-synaptic complex involving potassium channels and AMPAR. Genetic disruption of LGI1 protein in humans causes autosomal dominant lateral temporal lobe epilepsy ${ }^{26}$. The clinical spectrum of anti-LGI1 encephalitis usually comprises limbic encephalitis, hyponatremia and seizures. Half of the patients develop faciobrachial dystonic seizures, which are characterized by brief unilateral contractions of the arm (often evolving into the ipsilateral face or leg) that are shorter than three seconds and occur several times a day. Two-thirds of patients present with brain MRI hyperintensities in the medial temporal lobe (Figure 2). Paraneoplastic anti-LGI1 encephalitis is uncommon; however, patients should be screened for lung cancer ${ }^{27}$. Relapses may occur in up to $20 \%$ of patients ${ }^{28}$.

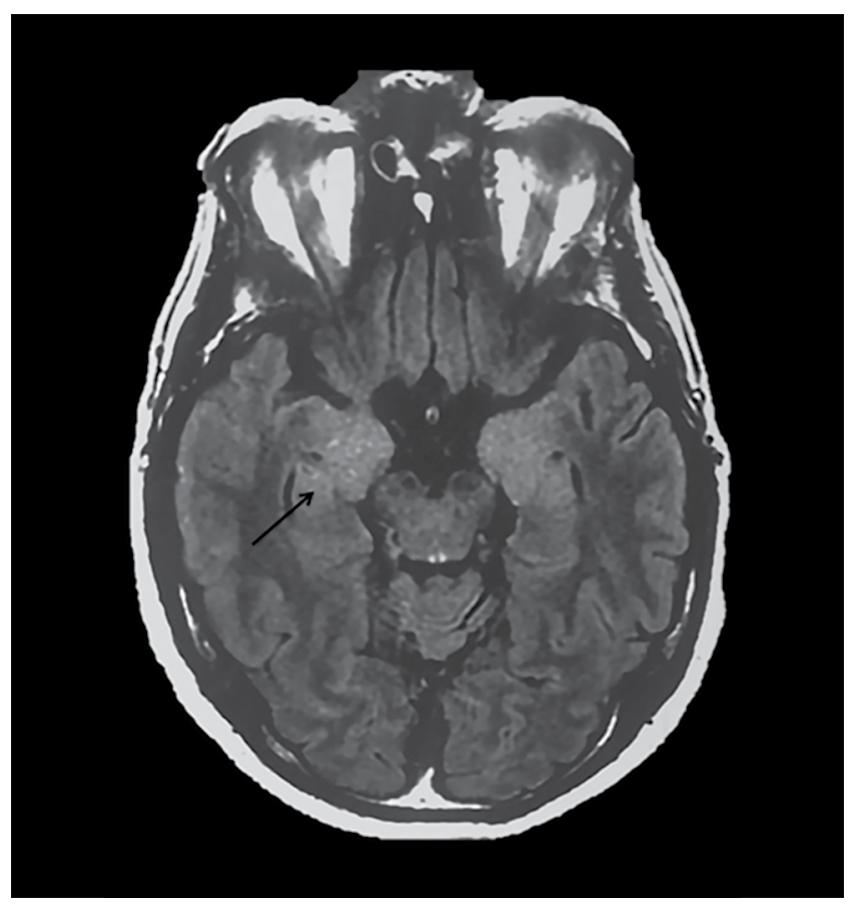

Figure 2. FLAIR sequence, brain MRI. Hippocampal hyperintensities in anti-LG1 encephalitis. 
The CASPR-2 is a juxtaparanodal adhesion molecule that interacts with contactin 2 and the cytoskeleton, and is involved in clustering of potassium channels in myelinated axons ${ }^{28}$. Anti-CASPR2 antibodies are associated with peripheral nerve hyperexcitability (myokymia, fasciculations, cramps) and encephalitis. Other symptoms include dysautonomia and insomnia (agrypnia excitata). Nearly one-third of patients develop Morvan's syndrome, a complex disorder affecting the peripheral and central nervous system that is characterized by distal movement disorders of the upper limbs, peripheral nerve hyperexcitability, dysautonomia, pain, and encephalitis ${ }^{24}$. Most individuals affected are male and one-third of them present with paraneoplastic manifestations, usually associated with thymoma, lung cancer or endometrial carcinoma ${ }^{27,26}$.

The clinical relevance of anti-VGKC antibodies against unknown target antigens is unclear. About half of patients with anti-VGKC encephalitis do not present antibodies against LGI1 or CASPR-2. These specific groups of patients develop a wide variety of clinical syndromes raising the question whether anti-VGKC antibodies are truly a marker of disease in these patients ${ }^{25}$. Anti-VGKC antibodies have been described, for example, in patients with Creutzfeldt-Jakob disease, suggesting that these antibodies might not be pathogenic. Anti-VGKC titers with negative anti-LGI1 and antiCASPR-2 antibodies are usually low $(<0.3 \mathrm{pM})$-although there is no clear cutoff value to differentiate between patients with and without AIE-thus it is not recommended to use them as evidence of immune-mediated pathogenesis ${ }^{22,29}$.

\section{Anti-GAD encephalitis}

Glutamic acid decarboxylase (GAD) is an enzyme that catalyzes the conversion of glutamic acid to the neurotransmitter GABA. Anti-GAD antibodies have been associated with other autoimmune disorders such as insulin-dependent diabetes mellitus. The main neurological syndromes associated with anti-GAD antibodies include stiff-person syndrome, cerebellar ataxia, epilepsy and limbic encephalitis ${ }^{30}$.

Stiff-person syndrome is a neurological disorder frequently associated with anti-GAD antibodies characterized by muscle stiffness resulting from co-contractions of agonist and antagonist muscles and painful spasms ${ }^{31}$. Another classic finding in this syndrome is the patient's pronounced startle responses.

Ataxia associated with anti-GAD antibodies is usually slowly progressive and evolves over months or years. Abnormal ocular movements with spontaneous downbeat nystagmus have also been described ${ }^{30}$. Nearly $7 \%$ of patients with antiGAD antibodies present with temporal lobe epilepsy or status epilepticus, and 5\% develop limbic encephalitis ${ }^{32,33}$.

Anti-GAD antibodies are rarely of paraneoplastic origin. Patients with stiff-person syndrome, cerebellar ataxia or other neurological syndromes typically associated with antiGAD antibodies do not need to be aggressively or repeatedly screened for cancer. However, the presence of anti-GAD antibodies in patients with limbic encephalitis or other classic paraneoplastic syndromes (paraneoplastic cerebellar degeneration, opsoclonus-myoclonus syndrome or paraneoplastic encephalomyelitis) is associated with a 10-fold increase in the risk of cancer and tumor screening is thus recommended ${ }^{34}$.

\section{Anti-GlyR encephalitis}

Glycine receptors (GlyR) are chloride channels that facilitate inhibitory neurotransmission in the brain and spinal cord $^{35}$. Anti-GlyR antibodies were first described in patients with progressive encephalomyelitis with rigidity and myoclonus and later in patients with stiff-person syndrome $e^{31,35,36}$. Recently, anti-GlyR antibodies have also been reported in patients with cerebellar ataxia and anti-GAD antibodies and patients with demyelinating diseases including optic neuritis and multiple sclerosis, but their clinical significance remains unclear $^{37,38}$. Anti-GlyR antibodies are usually not associated with tumors, although there have been reports of patients with underlying thymoma, small-cell lung cancer, breast cancer and chronic lymphocytic leukemia.

\section{Anti-DPPX encephalitis}

Dipeptidyl peptidase-like protein 6 (DPPX) is a subunit of Kv4.2 potassium channels expressed in the hippocampus, cerebellum, striatum, and myenteric plexus. Patients with anti-DPPX antibodies show neuropsychiatric symptoms (agitation and confusion), myoclonus, tremor, startle reflex, seizures, stiff-person syndrome and prodromal diarrhea of unknown etiology. In addition, they may have symptoms of dysautonomia including arrhythmias, thermodysregulation, diaphoresis, urinary symptoms and sleep disorders ${ }^{39,40}$.

The CSF analysis usually shows pleocytosis and increased protein concentrations. Functional tests in the serum of a DPPX-positive patient demonstrated increased excitability of enteric neurons and downregulation of DPPX and Kv4.2 from hippocampal neuron membranes, which is suggestive of the pathogenic effects of anti-DPPX antibodies in anti-DPPX encephalitis ${ }^{39}$.

\section{Encephalopathy associated with anti-IgLON5 antibodies}

The IgLON family member 5 (IgLON5) is a neuronal cell adhesion molecule of the immunoglobulin superfamily. Patients with anti-IgLON5 antibodies present with a unique non-REM (rapid eye movement) and REM parasomnia with obstructive sleep apnea, stridor, episodic central hypoventilation, dementia, gait instability, chorea, dysarthria, dysphagia, dysautonomia and supranuclear gaze palsy resembling that seen in classic tauopathy ${ }^{5,40}$. All published cases reported the presence of the alleles HLA-DQB1*0501 and HLA-DRB1*1001 suggesting genetic susceptibility to this disease. Neuropathological postmortem studies have shown a novel tauopathy with extensive neuronal deposits of 
hyperphosphorylated tau mainly involving the tegmentum of the brainstem and hypothalamus ${ }^{41}$. This novel encephalopathy provides an intriguing link between neurodegeneration and cell-surface autoimmunity. A recent study has shown that anti-IgLON5 antibodies recognize Ig-like domain 2 as an immunogenic region and causes irreversible internalization of IgLON5 from the neuronal membrane. These findings support a potential pathogenic role of anti-IgLON5 antibodies in the associated encephalopathy ${ }^{42}$.

\section{Anti-mGluR1 and anti-mGluR5 encephalitis}

Metabotropic glutamate receptor 1 (mGluR1) and metabotropic glutamate receptor 5 (mGluR5) are both G-protein-coupled receptors that share an $85 \%$ amino acid sequence homology. Both receptors are involved in modulating synaptic functions including long-term depression. While mGluR1 facilitates long-term depression at parallel fiber Purkinje cell synapses, which are critical for cerebellar motor learning, mGluR5 is more relevant for long-term depression in the hippocampus.

All patients with anti-mGluR1 antibodies develop cerebellar ataxia of subacute onset, and some may present with additional symptoms such as paranoia, dysgeusia, diplopia and cognitive deficits. Common tumors found to be associated with anti-mGluR1 antibodies are hematologic malignancies and prostate adenocarcinoma ${ }^{43}$. Response to immunotherapy is variable.

Patients with anti-mGluR5-abs present with a form of encephalitis named "Ophelia syndrome", a clinical syndrome that includes memory loss and psychosis in association with Hodgkin's lymphoma ${ }^{44}$. The outcome of reported cases is generally good after treatment of the lymphoma and immunotherapy ${ }^{44}$.

\section{Considerations on specific diagnostic methods for AIE}

Four different techniques are used to detect antibodies against cell surface antigens: cell-based assay (CBA) with HEK293 cells; tissue-based assay (TBA) on brain tissue of rodents using indirect immunohistochemistry or indirect immunofluorescence, and culture of dissociated hippocampal neurons from rats.

Cell-based assays are highly sensitive and robust signals are diagnostic of specific antigens ${ }^{45}$. The TBA provides an excellent screening approach as it can detect most currentlyknown antibodies and reveal new antibodies. Staining of live neuronal cell cultures are performed mainly in research laboratories and can be useful when TBAs and CBAs show conflicting results. It confirms that antibodies directed against neuronal surface antigens are present (Figure 3).

Testing for surface receptor antibodies should always be performed in both serum and CSF of the patients. This has several reasons: (1) in some specific syndromes (e.g. anti-NMDAR encephalitis) anti-neuronal antibodies may be found only in CSF (in a recent study $13 \%$ of anti-NMDAR encephalitis patients did not have detectable anti-NMDAR antibodies in serum ${ }^{46}$ ) while other antibodies (e.g. LGI1) may, in rare instances, be detectable only in serum. (2) Some patients may have a different antibody spectrum in serum and CSF, for example, some patients may have anti-NMDAR encephalitis in serum and CSF and, in addition, GABA-AR antibodies only in serum. In these cases, the antibody present in the CSF determines the clinical phenotype. (3) Antibodytiters in CSF correlate better with the clinical presentation than serum titers, and (4) serum testing harbors the risk of background reactivity that gives rise to false positive results. Recently, serum testing with CBA identified anti-NMDAR antibodies mainly of the IgA and IgM subclass in schizophrenia, Creutzfeldt-Jakob disease, depression, Parkinson's disease, and healthy individuals ${ }^{46}$. However, presence of these antibodies could not be shown in CSF and, therefore, the clinical significance of serum IgA and IgM anti-NMDAR antibodies remains to be clarified.

There are diagnostic challenges to testing for AIE in Brazil as commercial CBA and TBA kits are not approved for use by national regulatory authorities. Partner or research laboratories overseas perform most testing and some of these laboratories perform CBAs only. We currently recommend that samples from patients with clinical manifestations suggestive of AIE who tested negative by CBA should be referred to research laboratories that use other assessment methods.

Negative test results do not rule out immune-mediated disorders and nonspecific background signals may cause false positive test results. Steroid use may also interfere with the diagnostic test. Hence, test results should be interpreted with caution and put into the context of the clinical presentation.
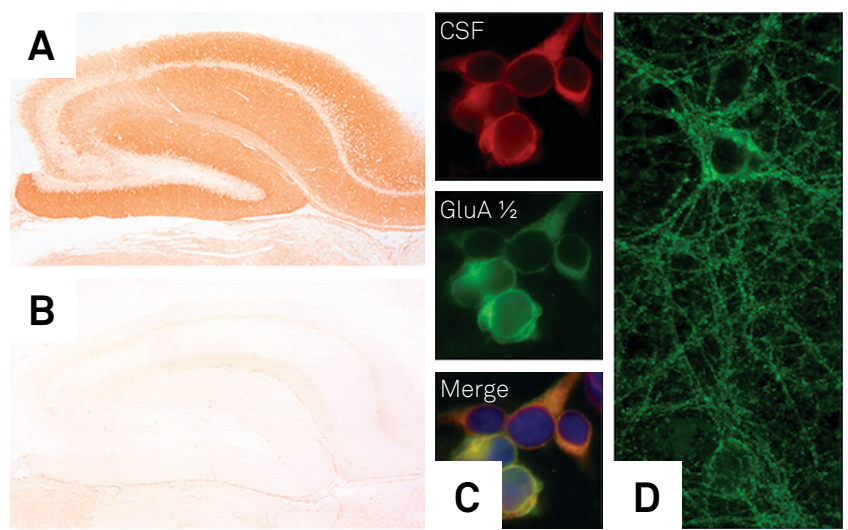

Figure 3. Techniques for the detection of anti-neuronal antibodies. Indirect immunohistochemistry on rat brain tissue with a serum of a patient with anti-NMDAR encephalitis shows strong labeling of hippocampal neurons (A) whereas a serum of a healthy individual is negative (B). In the cell-based assay, antibodies are identified on HEK293 cells transfected with related antigens. (C) red: CSF from a patient with AMPAR antibodies, green: commercial antibody against the GluA1/2 subunits of AMPARs). (D) Live hippocampal neuron culture; strong dot-like labeling of the neuronal membrane indicates antibodies against cell surface antigens. 
Because antibodies may remain positive despite clinical features, clinicians should focus on patient treatment rather than antibody titers.

\section{Differential diagnosis}

Differential diagnosis in anti-neuronal AIE includes Hashimoto's encephalopathy and other steroid-responsive encephalopathies, acute disseminated encephalomyelitis, neuromyelitis optica spectrum disorders, central nervous system vasculitis, neuropsychiatric lupus, angiocentric lymphoma, Rasmussen's encephalitis and febrile infectionrelated epilepsy syndrome. It is important to rule out HIV infection, syphilis, Creutzfeldt-Jakob disease, as well as human herpes virus-6-associated encephalitis in immunocompromised patients ${ }^{1,3,8,33}$.

Viral infections are known triggers for $\mathrm{AIE}^{3,4}$. It is believed that virus-mediated cerebral tissue damage may lead to antigen exposition that triggers the development of anti-neuronal antibodies. Herpes viruses may trigger autoimmunity to NMDAR, dopamine D2 receptor, GABA-AR and other synaptic proteins that have are not yet been characterized.

\section{Tumor investigation}

All patients with AIE should be screened for tumors at disease onset. The nature of the antibody, and to a lesser extent the clinical syndrome, determines the risk and type of an underlying malignancy ${ }^{47}$. Due to the low frequency of tumor association in patients with anti-LGI1 and anti-GAD antibodies, patient screening should be considered at disease onset, with no need for periodic screenings ${ }^{8}$. Tumor treatment is essential for neurological improvement ${ }^{25}$.

If initial tumor screening is negative but the patient has antibodies that are typically paraneoplastic (e.g. antiNMDAR in young adult women, anti-CASPR2, anti-AMPAR and anti-GABA-BR), screening should be repeated after three to six months, followed by screenings every six months for four years ${ }^{48}$.

Computed tomography (CT) of the chest should be performed; if negative, fluorodeoxyglucose positron emission tomography (FDG-PET) is indicated as it increases cancer detection by $20 \%{ }^{49}$. Mammograms followed by MRI are used for breast cancer screening. For the pelvic region and testes, ultrasound is the investigation of first choice followed by pelvic $\mathrm{CT}^{47}$. It is important to note that ovarian teratomas are not seen in FDG-PET scans.

\section{Treatment and prognosis}

Various treatment approaches including corticosteroids, intravenous immunoglobulin, plasma exchange, rituximab and cyclophosphamide are currently used ${ }^{13}$. Data on treatment response and prognosis are mostly available for antiNMDAR encephalitis ${ }^{50}$.

Evidence suggests that early immunotherapy improves outcome ${ }^{3}$, thus treatment for AIE should not be delayed. Patients should receive either methylprednisolone $1 \mathrm{~g}$ IV for 3-5 days and intravenous immunoglobulin $(0.4 \mathrm{~g} / \mathrm{kg} /$ day for five days) or methylprednisolone and plasmapheresis. We favor the use of plasmapheresis in patients with refractory seizures and severe dysautonomia, although there is no compelling evidence of superiority of any approach. If an associated tumor is detected, oncologic management (chemotherapy or tumor resection) is important for improvement.

Autoimmune encephalitis patients who fail to improve after 10-14 days should receive second-line therapies such as rituximab or cyclophosphamide, or both ${ }^{3,13}$. Specialized centers usually prescribe rituximab $\left(375 \mathrm{mg} / \mathrm{m}^{2}\right)$ weekly for four weeks and cyclophosphamide $\left(750 \mathrm{mg} / \mathrm{m}^{2}\right)$ for six months in patients older than 16 years. Younger patients should receive rituximab alone ${ }^{3}$.

Better prognosis has been associated with early treatment, no requirement for intensive care admission and nonparaneoplastic $\mathrm{AIE}^{20}$. The treatment response and relapse rate vary among patients with AIE. Half of the patients with anti-NMDAR encephalitis fail initial immunotherapy and may require second-line treatment options, with relapses occurring in $12 \%$. Relapses may occur in $31 \%$ of patients with anti-LGI1 encephalitis and 10\% of those with anti-CASPR2 encephalitis, sometimes years after the first episode. About $33 \%$ of the patients with anti-LGI1 encephalitis are left disabled, mostly due to memory problems.

\section{FINAL REMARKS}

Autoimmune encephalitis may present with a wide variety of symptoms of either acute or subacute onset. The diagnosis should not rely solely on antibody testing as patients with AIE may be seronegative. Clinicians must be aware of the different laboratory assessment methods available as well as proper interpretation of results. Clinical presentation and physical examination are of extreme importance in AIE. Patients benefit from early aggressive treatment and relapses may occur.

\section{References}

\footnotetext{
1. Granerod J, Ambrose HE, Davies NW, Clewley JP, Walsh AL, Morgan

$D$ et al. Causes of encephalitis and differences in their clinical presentations in England: A multicentre, population-based prospective study. Lancet Infect Dis. 2010;10(12):835-44. https://doi.org/10.1016/S1473-3099(10)70222-X
} that of individual viral etiologies in young individuals enrolled in the California Encephalitis Project. Clin Infect Dis. 2012;54(7):899-904. https://doi.org/10.1093/cid/cir1038 
3. Graus F, Titulaer MJ, Balu R, Benseler S, Bien CG, Cellucci Tet al. A clinical approach to diagnosis of autoimmune encephalitis. Lancet Neurol. 2016;15(4):391-404. https://doi.org/10.1016/S1474-4422(15)00401-9

4. Linnoila JJ, Binnicker MJ, Majed M, Klein CJ, McKeon A. CSF herpes virus and autoantibody profiles in the evaluation of encephalitis. Neurol - Neuroimmunol Neuroinflammation. 2016;3(4):e245. https://doi.org/10.1212/NXI.0000000000000245

5. Sabater L, Gaig C, Gelpi E, Bataller L, Lewerenz J, Torres-Vega E et al. A novel non-rapid-eye movement and rapid-eye-movement parasomnia with sleep breathing disorder associated with antibodies to IgLON5: a case series, characterisation of the antigen, and post-mortem study. Lancet Neurol. 2014;13(6):575-86. https://doi.org/10.1016/S1474-4422(14)70051-1

6. Lancaster E, Dalmau J. Neuronal autoantigens: pathogenesis, associated disorders and antibody testing. Nat Rev Neurol. 2012;8(7):380-90. https://doi.org/10.1038/nrneurol.2012.99

7. Coevorden-Hameete MH, de Graaff E, Titulaer MJ, Hoogenraad CC, Sillevis Smitt PE. Molecular and cellular mechanisms underlying anti-neuronal antibody mediated disorders of the central nervous system. Autoimmun Rev. 2014;13(3):299-312. https://doi.org/10.1016/j.autrev.2013.10.016

8. Leypoldt F, Wandinger K-P, Bien CG, Dalmau J.

Autoimmune Encephalitis. Eur Neurol Rev. 2013;8(1):31-7. https://doi.org/10.17925/ENR.2013.08.01.31

9. Davis R, Dalmau J. Autoimmunity, seizures, and status epilepticus. Epilepsia. 2013;54(6 Suppl 6):46-9. https://doi.org/10.1111/epi.12276

10. Tobin WO, Lennon VA, Komorowski L, Probst C, Clardy SL, Aksamit AJ et al. DPPX potassium channel antibody: frequency, clinical accompaniments, and outcomes in 20 patients. Neurology. 2014; 83(20):1797-803. https://doi.org/10.1212/WNL.0000000000000991

11. Dalmau J, Tüzün E, Wu HY, Masjuan J, Rossi JE, Voloschin A et al. Paraneoplastic anti- N -methyl-D-aspartate receptor encephalitis associated with ovarian teratoma. Ann Neurol. 2007;61(1):25-36. https://doi.org/10.1002/ana.21050

12. Dalmau J, Lancaster E, Martinez-Hernandez E, Rosenfeld MR, Balice-Gordon R. Clinical experience and laboratory investigations in patients with antiNMDAR encephalitis. Lancet Neurol. 2011;10(1):63-74. https://doi.org/10.1016/S1474-4422(10)70253-2PMID:21163445

13. Titulaer MJ, McCracken L, Gabilondo I, Armangué T, Glaser C, lizuka T et al. Treatment and prognostic factors for long-term outcome in patients with anti-NMDA receptor encephalitis: an observational cohort study. Lancet Neurol. 2013;12(2):157-65. https://doi.org/10.1016/S1474-4422(12)70310-1

14. Schmitt SE, Pargeon K, Frechette ES, Hirsch LJ. Extreme delta brush: a unique EEG pattern in adults with anti-NMDA receptor encephalitis. Neurology. 2012;79:1094-100. https://doi.org/10.1212/WNL.0b013e3182698cd8

15. Höftberger R, Sonderen A, Leypoldt F, Houghton D, Geschwind M, Gelfand J et al. Encephalitis and AMPA receptor antibodies: novel findings in a case series of 22 patients. Neurology. 2015;84(24):2403-12. https://doi.org/10.1212/WNL.0000000000001682

16. Petit-Pedrol M, Armangue T, Peng X, Bataller L, Cellucci T, Davis R et al. Encephalitis with refractory seizures, status epilepticus, and antibodies to the GABAA receptor: a case series, characterisation of the antigen, and analysis of the effects of antibodies. Lancet Neurol. 2014;13(3):276-86. https://doi.org/10.1016/S1474-4422(13)70299-0

17. Spatola M, Petit-Pedrol M, Simabukuro MM, Armangue T, Castro FJ, Barcelo Artigues MI et al. Investigations in GABAA receptor antibody-associated encephalitis. Neurology. 2017;88 (11):1012-20. https://doi.org/10.1212/WNL.0000000000003713

18. Ohkawa T, Satake S, Yokoi N, Miyazaki Y, Ohshita T, Sobue $\mathrm{G}$ et al. Identification and characterization of $\mathrm{GABA}(\mathrm{A})$ receptor autoantibodies in autoimmune encephalitis. J Neurosci. 2014;34(24):8151-63. https://doi.org/10.1523/JNEUROSCI.4415-13.2014

19. Lancaster E, Lai M, Peng X, Hughes E, Constantinescu R, Raizer $J$ et al. Antibodies to the GABA(B) receptor in limbic encephalitis with seizures: case series and characterisation of the antigen. Lancet Neurol. 2010;9(1):67-76. https://doi.org/10.1016/S1474-4422(09)70324-2

20. Höftberger R, Titulaer MJ, Sabater L, Dome B, Rózsás A, Hegedus B et al. Encephalitis and GABAB receptor antibodies: novel findings in a new case series of 20 patients. Neurology. 2013;81(17):1500-6. https://doi.org/10.1212/WNL.0b013e3182a9585f

21. Lancaster E, Martinez-Hernandez E, Dalmau J. Encephalitis and antibodies to synaptic and neuronal cell surface proteins. Neurology. 2011;77(2):179-89. https://doi.org/10.1212/WNL.0b013e318224afde

22. Sonderen A, Schreurs MW, Bruijn MA, Boukhrissi S, Nagtzaam MM, Hulsenboom ES et al. The relevance of VGKC positivity in the absence of LGI1 and Caspr2 antibodies. Neurology. 2016;86(18):1692-9. https://doi.org/10.1212/WNL.0000000000002637

23. Lilleker JB, Jones MS, Mohanraj R. VGKC complex antibodies in epilepsy: diagnostic yield and therapeutic implications. Seizure. 2013;22(9):776-9. https://doi.org/10.1016/j.seizure.2013.06.004

24. Irani SR, Pettingill P, Kleopa KA, Schiza N, Waters P, Mazia C et al. Morvan syndrome: clinical and serological observations in 29 cases. Ann Neurol. 2012;72(2):241-55. https://doi.org/10.1002/ana.23577

25. van Sonderen A, Schreurs MWJ, Wirtz PW, Sillevis Smitt PAE, Titulaer MJ. From VGKC to LGI1 and Caspr2 encephalitis: the evolution of a disease entity over time. Autoimmun Rev. 2016;15(10):970-4. https://doi.org/10.1016/j.autrev.2016.07.018

26. Lancaster E, Huijbers MG, Bar V, Boronat A, Wong A, Martinez-Hernandez E et al. Investigations of caspr2, an autoantigen of encephalitis and neuromyotonia. Ann Neurol. 2011;69(2):303-11. https://doi.org/10.1002/ana.22297

27. Sonderen A, Thijs RD, Coenders EC, Jiskoot LC, Sanchez E, Bruijn MA et al. Anti-LGl1 encephalitis: clinical syndrome and long-term follow-up. Neurology. 2016;87(14):1449-56. https://doi.org/10.1212/WNL.0000000000003173

28. Poliak S, Salomon D, Elhanany H, Sabanay H, Kiernan B, Pevny L et al. Juxtaparanodal clustering of Shaker-like K+ channels in myelinated axons depends on Caspr2 and TAG-1.J Cell Biol. 2003;162(6):1149-60. https://doi.org/10.1083/jcb.200305018

29. Sonderen A, Petit-Pedrol M, Dalmau J, Titulaer MJ. The value of LGI1, Caspr2 and voltage-gated potassium channel antibodies in encephalitis. Nat Rev Neurol. 2017;13(5):290-301. https://doi.org/10.1038/nrneurol.2017.43

30. Vale TC, Pedroso JL, Alquéres RA, Dutra LA, Barsottini OGP. Spontaneous downbeat nystagmus as a clue for the diagnosis of ataxia associated with anti-GAD antibodies. J Neurol Sci. 2015;359(1-2):21-3. https://doi.org/10.1016/j.jns.2015.10.024

31. Alexopoulos H, Akrivou S, Dalakas MC. Glycine receptor antibodies in stiff-person syndrome and other GAD-positive CNS disorders. Neurology. 2013;81(22):1962-4. https://doi.org/10.1212/01.wnl.0000436617.40779.65

32. Khawaja AM, Vines BL, Miller DW, Szaflarski JP, Amara AW. Refractory status epilepticus and glutamic acid decarboxylase antibodies in adults: presentation, treatment and outcomes. Epileptic Disord. 2016;18(1):34-43. https://doi.org/10.1684/epd.2016.0797

33. Saiz A, Blanco Y, Sabater L, González F, Bataller L, Casamitjana $R$ et al. Spectrum of neurological syndromes associated with glutamic acid decarboxylase antibodies: diagnostic clues for this association. Brain. 2008;131(10):2553-63. https://doi.org/10.1093/brain/awn183

34. Ariño H, Höftberger R, Gresa-Arribas N, Martínez-Hernández E, Armangue T, Kruer MC et al. Paraneoplastic Neurological Syndromes and Glutamic Acid Decarboxylase Antibodies. JAMA Neurol. 2015;72(8):1-8. https://doi.org/10.1001/jamaneurol.2015.0749 
35. Hutchinson M, Waters P, McHugh J, Gorman G, O'Riordan S, Connolly $S$ et al. Progressive encephalomyelitis, rigidity, and myoclonus: a novel glycine receptor antibody. Neurology. 2008;71(16):1291-2. https://doi.org/10.1212/01.wnl.0000327606.50322.f0

36. McKeon A, Martinez-Hernandez E, Lancaster E, Matsumoto JY, Harvey RJ, McEvoy KM et al. Glycine receptor autoimmune spectrum with stiff-man syndrome phenotype. JAMA Neurol. 2013;70(1):44-50. https://doi.org/10.1001/jamaneurol.2013.574

37. Ariño H, Gresa-Arribas N, Blanco Y, Martínez-Hernández E, Sabater L, Petit-Pedrol M et al. Cerebellar ataxia and glutamic acid decarboxylase antibodies. JAMA Neurol. 2014;71(8):1009-16. https://doi.org/10.1001/jamaneurol.2014.1011

38. Martinez-Hernandez E, Sepulveda M, Rostásy K, Höftberger R, Graus F, Harvey RJ et al. Antibodies to aquaporin 4, myelin-oligodendrocyte glycoprotein, and the glycine receptor $\alpha 1$ subunit in patients with isolated optic neuritis. JAMA Neurol. 2015;72(2):187-93. https://doi.org/10.1001/jamaneurol.2014.3602

39. Piepgras J, Höltje M, Michel K, Li Q, Otto C, Drenckhahn C et al. Anti-DPPX encephalitis: pathogenic effects of antibodies on gut and brain neurons. Neurology. 2015;85(10):890-7. https://doi.org/10.1212/WNL.0000000000001907

40. Boronat A, Gelfand JM, Gresa-Arribas N, Jeong HY, Walsh M, Roberts $K$ et al. Encephalitis and antibodies to dipeptidyl-peptidase-like protein-6, a subunit of Kv4.2 potassium channels. Ann Neurol. 2013;73(1):120-8. https://doi.org/10.1002/ana.23756

41. Gelpi E, Höftberger R, Graus F, Ling H, Holton JL, Dawson Tet al. Neuropathological criteria of anti-IgLON5-related tauopathy. Acta Neuropathol. 2016;132(4):531-43. https://doi.org/10.1007/s00401-016-1591-8

42. Gaig C, Graus F, Compta Y, Högl B, Bataller L, Brüggemann $\mathrm{N}$ et al. Clinical manifestations of the anti-IgLON5 disease. Neurology. 2017;88(18):1736-43. https://doi.org/10.1212/WNL.0000000000003887
43. Lopez-Chiriboga AS, Komorowski L, Kümpfel T, Probst C, Hinson SR, Pittock SJ et al. Metabotropic glutamate receptor type 1 autoimmunity. Neurology. 2016;86(11):1009-13. https://doi.org/10.1212/WNL.0000000000002476

44. Lancaster E, Martinez-Hernandez E, Titulaer MJ, Boulos M, Weaver $\mathrm{S}$, Antoine JC et al. Antibodies to metabotropic glutamate receptor 5 in the Ophelia syndrome. Neurology. 2011;77(18):1698-701. https://doi.org/10.1212/WNL.0b013e3182364a44

45. Gresa-Arribas N, Titulaer MJ, Torrents A, Aguilar E, McCracken L, Leypoldt F et al. Antibody titres at diagnosis and during follow-up of anti-NMDA receptor encephalitis: a retrospective study. Lancet Neurol. 2014;13(2):167-77. https://doi.org/10.1016/S1474-4422(13)70282-5

46. Dahm L, Ott C, Steiner J, Stepniak B, Teegen B, Saschenbrecker $S$ et al. Seroprevalence of autoantibodies against brain antigens in health and disease. Ann Neurol. 2014;76(1):82-94. https://doi.org/10.1002/ana.24189

47. Titulaer MJ, Soffietti R, Dalmau J, Gilhus NE, Giometto B, Graus F et al. Screening for tumours in paraneoplastic syndromes: report of an EFNS Task Force. Eur J Neurol. 2011;18(1):19-e3. https://doi.org/10.1111/j.1468-1331.2010.03220.x

48. Dalmau J, Rosenfeld MR. Paraneoplastic syndromes of the CNS. Lancet Neurol. 2008;7(4):327-40. https://doi.org/10.1016/S1474-4422(08)70060-7

49. McKeon A, Apiwattanakul M, Lachance DH, Lennon VA, Mandrekar JN, Boeve BF. Positron emission tomography-computed tomography in paraneoplastic neurologic disorders. Arch Neurol. 2010;67(3):322. https://doi.org/10.1001/archneurol.2009.336

50. Vincent A, Bien CG, Irani SR, Waters P. Autoantibodies associated with diseases of the CNS: new developments and future challenges. Lancet Neurol. 2011;10(8):759-72. https://doi.org/10.1016/S1474-4422(11)70096-5 